\title{
Changes in the intestinal absorption mechanism of icariin in the nanocavities of cyclodextrins
}

\author{
This article was published in the following Dove Press journal: \\ International Journal of Nanomedicine \\ I August 2012 \\ Number of times this article has been viewed
}

\author{
Ye Zhang' \\ Qiang-Song Wang' \\ Yuan-Lu Cui' \\ Fan-Cui Meng ${ }^{2}$ \\ Ke-Ming Lin'
}

'Tianjin State Key Laboratory of Modern Chinese Medicine, Tianjin University of Traditional Chinese Medicine, Tianjin, People's Republic of China; ${ }^{2}$ Tianjin Key Laboratory of Molecular Design and Drug Discovery, Tianjin Institute of Pharmaceutical Research, Tianjin, People's Republic of China
Correspondence: Yuan-Lu Cui Tianjin State Key Laboratory of Modern Chinese Medicine, Tianjin University of Traditional Chinese Medicine, No 88 Yuquan Road, Nankai District, Tianjin, 300193 , People's Republic of China

$\mathrm{Tel}+862259596170$

Fax +8622595961 70

Email cuiyl@tju.edu.cn
Abstract: Icariin is a bioactive herbal ingredient isolated from Herba epimedii, which has been widely used for the treatment of osteoporosis and male sexual dysfunction in traditional Chinese medicine. The major objective of this work is to investigate the different enhancing effects of $\beta$-cyclodextrin ( $\beta$-CD) and hydroxypropyl- $\beta$-cyclodextrin (HP- $\beta$-CD) on the intestinal absorption of icariin, and to identify the molecular mechanisms of this action. Host-guest-type interactions of icariin with cyclodextrins nanocavities were unambiguously demonstrated by the phase-solubility diagram, ultraviolet spectroscopy, Fourier transform infrared spectroscopy, differential scanning calorimetry, X-ray powder diffractometry, and two dimensional proton nuclear magnetic resonance rotating-frame Overhauser effect spectroscopy. These results were further supported using molecular modeling studies. The rat single-pass intestinal perfusion model showed that the absorption of icariin was affected by P-glycoprotein (Pgp). The icariin/ HP- $\beta$-CD inclusion complex provided greater enhancement in the intestinal absorption than the icariin/ $\beta$-CD inclusion complex. Therefore, the enhancing effect was involved in a solubilizing effect and/or Pgp inhibitory effect. Finally, fluorescence anisotropy measurements and Pgp adenosine triphosphatase (ATPase) assay demonstrated that $\beta-C D$ exhibited no effect on Pgp, while HP- $\beta-C D$ showed inhibition by restraining the Pgp ATPase activity rather than changing the fluidity of cell membrane.

Keywords: icariin, cyclodextrin, inclusion complex, molecular modeling, P-glycoprotein (Pgp), intestinal absorption

\section{Introduction}

Icariin (Figure 1A) is a major constituent of flavonoids isolated from Epimedium brevicornum Maxim, which has been used in traditional Chinese medicine to enhance male sexual function for over 2000 years. Herba epimedii and its complex formulations, such as Xianling Gubao capsules, are widely used in China for the treatment of osteoporosis, coronary artery disease, male sexual dysfunction, acute myocardial ischemia, and asthmatic cough. ${ }^{1-4}$ Modern pharmacology shows that icariin performs a lot of pharmacological and biological activities, which include preventing osteoporosis, protecting neurons, facilitating penile erection, and performing anti-cancer, anti-depression, and hypouricemic action. ${ }^{5-10}$ However, poor bioavailability of icariin is a significant barrier to its clinical application. ${ }^{11-13}$ It should be noted that possible interactions of icariin with P-glycoprotein (Pgp) that are closely involved in the absorption and exsorption of structurally and pharmacologically unrelated drugs in the intestine are taken into consideration. 


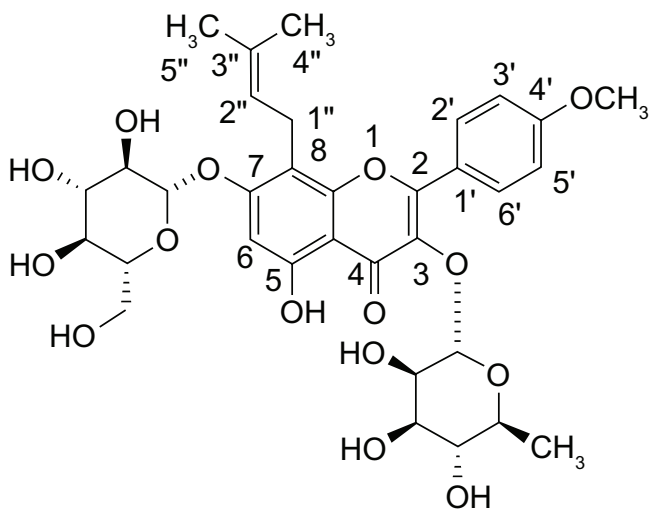

A(icariin)

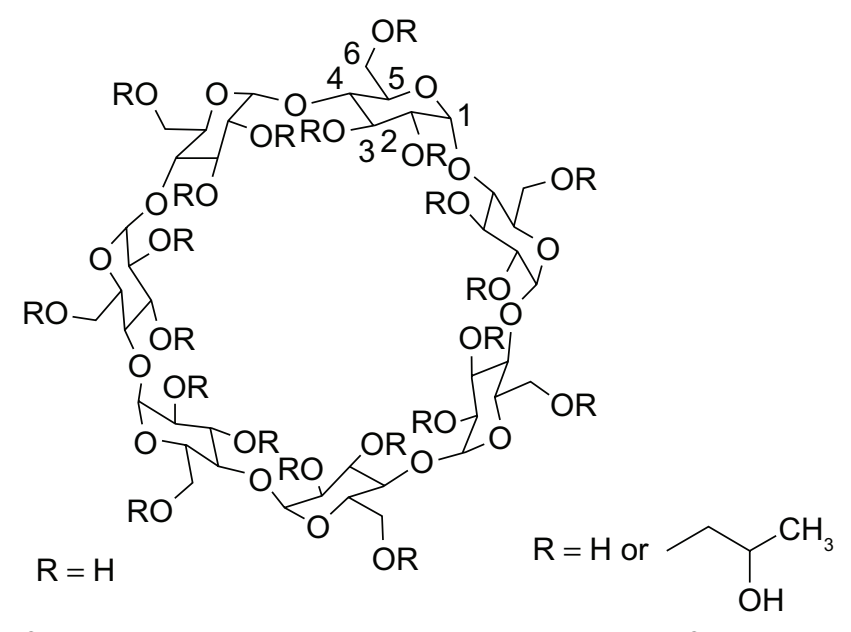

$B(\beta-C D)$

$C(H P-\beta-C D)$

Figure I Structure and proton labeling of $(\mathbf{A})$ icariin, (B) $\beta-C D$ and $(\mathbf{C}) \mathrm{HP}-\beta-\mathrm{CD}$.

Abbreviations: $\beta-C D$, beta-cyclodextrin; HP- $\beta-C D$, hydroxypropyl-beta-cyclodextrin.

Cyclodextrins (CDs) are cyclic polysaccharides mainly composed of six to eight D-glucose monomers linked by $\alpha-1$, 4-glucosidic bonds. They have hydrophobic nanocavities and hydrophilic outer surfaces, and can encapsulate hydrophobic guest molecules to form host-guest complexes or supermolecular species. This usually enhances drug solubility in water and affects the physicochemical properties of the drug. ${ }^{14,15}$ The most widely used natural cyclodextrin, $\beta-\mathrm{CD}$ (Figure 1B), is limited in its pharmaceutical applications due to its limited aqueous solubility $(1.85 \mathrm{~g} / 100 \mathrm{~mL}) .{ }^{16,17}$ Therefore, chemically modified CDs have been synthesized to overcome this problem (eg, methylated, hydroxypropylated, and sulfobutyl ether CD derivatives). ${ }^{18,19}$ Hydroxypropyl$\beta$-cyclodextrin (HP- $\beta$-CD, Figure 1C) has been extensively investigated for its relatively high water solubility, low toxicity, and satisfactory inclusion ability. ${ }^{20-22}$ Several commercial formulations are composed of cyclodextrin inclusion complexes, illustrating the usefulness of this approach..$^{23-26}$ Additionally, many references have reported that the inhibitory mechanisms of Pgp by methylated $\beta-\mathrm{CD}$ were releasing transporters, ${ }^{27}$ altering cholesterol levels, ${ }^{28,29}$ increasing plasma membrane fluidity, ${ }^{30}$ and so on. We therefore speculate that HP- $\beta$-CD might inhibit Pgp activity.

In a more general attempt to optimize the pharmaceutical properties and the absorption of icariin, this work aimed to investigate the effectiveness of $\beta-C D$ and HP- $\beta-C D$ in improving the intestinal absorption of icariin. The phase solubility technique and two-dimensional (2D) proton nuclear magnetic resonance ( ${ }^{1} \mathrm{H}$ NMR) spectroscopy (rotating-frame Overhauser effect spectroscopy, ROESY) were used to investigate the interactions of icariin with
$\beta-C D$ or HP- $\beta-C D$ in an aqueous solution. Solid inclusion complexes were prepared by a freeze-drying method and were characterized by Fourier transform infrared (FTIR) spectroscopy, differential scanning calorimetry (DSC), and powder X-ray diffractometry (XRD). The main purpose of this study was to investigate the different enhancing effects between $\beta-C D$ and HP- $\beta$-CD on the intestinal absorption of icariin, to identify both $\beta-C D$ and HP- $\beta-C D$ as solubility enhancers, and to identify HP- $\beta-C D$ as a Pgp inhibitor. Moreover, the mechanism by which HP- $\beta-C D$ affects Pgp inhibition is investigated by membrane anisotropy measurements and Pgp ATPase assay.

\section{Materials and methods Materials}

Icariin was bought from Nanjing Chongyuan biotechnology Co (Nanjing, China). $\beta-C D$ (molecular mass, 1135) was kindly donated by Maxdragon International Co (Guangzhou, China). HP- $\beta-C D$ (molecular mass, 1540) was purchased from Wacker Chemie AG (Munich, Germany). Pgp-Glo Assay kit was from Promega Co (Madison, WI). 1,2dipalmitoyl-sn-glycero-3-phosphocholine (DPPC; molecular mass, 734.04, batch number 78K5203), and 1,6-diphenyl1,3,5-hexatriene (DPH; molecular mass, 232.32, batch number MKBD1354V) were purchased from Sigma-Aldrich Co (St Louis, MO). Acetonitrile and methanol for highperformance liquid chromatography (HPLC) analysis were obtained from Merck Co (Darmstadt, Germany). Deionized water was obtained from a Milli-Q water purification system (Molsheim, France). Other chemicals were commercially available and used as received. 


\section{Phase solubility studies}

Phase solubility studies were carried out in water according to the method previously reported by Calabrò et al. ${ }^{31}$ Briefly, excessive amounts of icariin were added to a series of capped tubes containing increasing amounts of $\beta-C D$ or HP- $\beta-C D$ $(0-18 \mathrm{mM})$. The suspensions were shaken at room temperature for 2 days. After equilibrium was attained, the samples were filtered through $0.45 \mu \mathrm{m}$ pore size Millipore syringe filters and assayed by HPLC method. The HPLC analysis was performed on a Waters 2695 system (Waters, Milford, MA) equipped with a 2487 dual $\lambda$ absorbance detector (Waters). The samples of $10 \mu \mathrm{L}$ were injected onto an ODS-2 Hypersil reversed-phase C18 column $(250 \mathrm{~mm} \times 4.6 \mathrm{~mm}, 5 \mu \mathrm{m})$ at $25^{\circ} \mathrm{C}$. All samples were detected with an ultraviolet (UV) detector at $268 \mathrm{~nm}$. The mobile phase consisted of a mixture of acetonitrile/water $(30: 70, \mathrm{v} / \mathrm{v})$. The flow rate was $1.0 \mathrm{~mL} /$ minute. Each test group was performed in triplicate. Phase solubility profiles were obtained by plotting the solubility of icariin versus the concentration of $\beta-\mathrm{CD}$ or HP- $\beta$-CD.

\section{Preparation of the inclusion complexes}

The inclusion complexes were prepared by way of a freezedrying method at a 1:1 molar ratio based on the results of phase solubility studies. In short, icariin was dissolved with small amounts of methanol at $45^{\circ} \mathrm{C}$. The solution was added to a $\beta-\mathrm{CD}$ or HP- $\beta-\mathrm{CD}$ water solution, and the resulting suspension kept on stirring for 8 hours before cooling slowly to room temperature. The prepared suspension was quickly filtered through $0.45 \mu \mathrm{m}$ pore size Millipore syringe filters to remove any free icariin. The suspension was then frozen and lyophilized in a Thermo Savant ModulyoD Freeze Dryer (Thermo Scientific, Waltham, MA) at $-45^{\circ} \mathrm{C}$ and 100 mbar to obtain the inclusion complexes. In parallel, physical mixtures containing the same ratios of icariin and $\beta-C D$ or HP- $\beta-C D$ were prepared in a mortar.

\section{Characterization of the inclusion complexes}

UV spectroscopic analysis of icariin $(0.01 \mathrm{mmol} / \mathrm{L})$ with increasing amounts of $\beta-\mathrm{CD}$ and HP- $\beta-\mathrm{CD}$ in $50 \%$ DMSO $(\mathrm{v} / \mathrm{v})$ was done using a Flexstation 3 microplate reader (Molecular Devices, Sunnyvale, CA) at room temperature.

FTIR spectra were recorded on $\mathrm{KBr}$ pellets in the $3900-400 \mathrm{~cm}^{-1}$ wave number range using a Bio-Rad FTS 3000 spectrophotometer (Bio-Rad, Richmond, CA).

DSC was recorded on a Perkin-Elmer DSC 7 (PerkinElmer, Norwalk, CT). Samples ranging between 5-10 mg were sealed in aluminum pans and heated at a rate of $10^{\circ} \mathrm{C} /$ minute from room temperature to $260^{\circ} \mathrm{C}$ and under $\mathrm{N}_{2}$ flow (100 mL/minute).

XRD was measured in the range of $2 \theta=4-54^{\circ}$ by step scanning on the Rigaku D/MAX-2500 diffractometer (Rigaku Co, Tokyo, Japan) with $\mathrm{Cu} \mathrm{K} \alpha$ radiation operating at $40 \mathrm{kV}$ and $100 \mathrm{~mA}$, and a scanning rate of $2 \%$ minute.

ROESY experiments were obtained on Bruker Avance DRX500 spectrometer (Bruker Analytik, Rheinstetten, Germany) at $298 \mathrm{~K}$ in $\mathrm{D}_{2} \mathrm{O}$ and DMSO-d 6 (50:50, v/v). Samples were equilibrated for at least 24 hours before measurement.

\section{Absorption studies}

\section{Animals}

Male Sprague Dawley rats, weighing 200-220 g, were obtained from Tianjin Shanchuanhong Laboratory Animal Technology Co, Ltd (SCXK 2009-0001; Tianjin, China). The rats were housed under standard conditions and fasted overnight with free access to water until the experiment. Animal experiments were carried out in accordance with the National Institutes of Health Guide for Care and Use of Laboratory Animals, and the protocol was approved by the Animal Ethics Committee at the Tianjin University of Traditional Chinese Medicine.

\section{Perfusion preparation}

The Krebs-Ringer's buffer, containing $10 \mu \mathrm{g} / \mathrm{mL}$ of phenol red, was used as the perfusion solution. Icariin $(8 \mu \mathrm{g} / \mathrm{mL})$ in the absence or presence of Pgp inhibitor, verapamil $(16 \mu \mathrm{g} / \mathrm{mL})$, or an equivalent amount of the inclusion complexes were dissolved in $1000 \mathrm{~mL}$ of perfusion solution.

\section{Rat experiment}

The rat single-pass intestinal perfusion model suggested in this paper is illustrated in Figure 2. The experiment was performed according to the reported method. ${ }^{32,33}$ After fasting

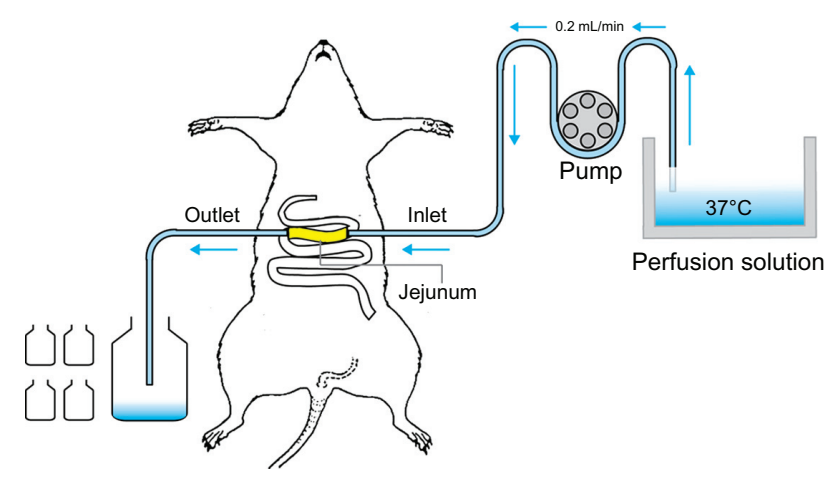

Figure 2 Illustration of the single-pass intestinal perfusion model. 
overnight, male Sprague Dawley rats were randomly assigned to different experimental groups $(n=4)$. Rats were anesthetized with urethane $(1 \mathrm{~g} / \mathrm{kg}$, intraperitoneally) and affixed supine on a surface under suitable lighting to maintain body temperature. The jejunum was exposed by a midline abdominal incision, and two polyethylene cannulae (outer diameter, $5 \mathrm{~mm}$; inner diameter, $3 \mathrm{~mm}$ ) were inserted through small slits at the proximal and distal ends (about $10 \mathrm{~cm}$ ). To clear the gut, saline solution at $37^{\circ} \mathrm{C}$ was passed slowly through it until the effluent was clear. The perfusion solutions were incubated in a $37^{\circ} \mathrm{C}$ water bath. The perfusion flow rate used was $0.2 \mathrm{~mL} / \mathrm{min}$, which was 10 times lower than that used in humans $(2-3 \mathrm{~mL} / \mathrm{min})$. The outflow solution was collected every $15 \mathrm{~min}$ for $120 \mathrm{~min}$, starting $15 \mathrm{~min}$ after the initiation of the perfusion when steady state had been achieved (as assessed by the inlet/outlet concentration ratio of icariin, which approached 1 at a steady state). The perfusate samples were immediately assayed by HPLC. The length of the perfused intestinal segment was measured accurately at the termination of the experiment.

\section{HPLC assay}

The HPLC method described above was used. Linearity was demonstrated over a concentration range of $0.82-6.59 \mu \mathrm{g} / \mathrm{mL}$ ( $R=0.9998)$ for icariin in a Krebs-Ringer's buffer with a retention time of 12.4 minutes, and $1-25 \mu \mathrm{g} / \mathrm{mL}(R=0.9997)$ for phenol red with a retention time of 4.4 minutes. The method was precise in the sample analysis with coefficient of variations of $0.74 \%, 0.55 \%$, and $1.20 \%$ at $1.65,3.30$, and $6.59 \mu \mathrm{g} / \mathrm{mL}$ for icariin, respectively; and coefficient of variations of $2.07 \%, 0.59 \%$, and $0.71 \%$ at $2.5,10$, and $25 \mu \mathrm{g} / \mathrm{mL}$ for phenol red, respectively. The method was also reproducible with within-day and between-day variations of $4.13 \%$ and $4.20 \%$ for icariin and $3.39 \%$ and $3.61 \%$ for phenol red, respectively.

\section{Data analysis}

The netwater flux, resulting from both water absorption and efflux in the intestinal segment, was determined by measurement of phenol red, a nonabsorbed, nonmetabolized marker. The measured $\mathrm{C}_{\text {out }}{ }^{\prime} / \mathrm{C}_{\text {in }}{ }^{\prime}$ ratio was corrected for water transport according to the following equation:

$$
\mathrm{C}_{\text {out }}{ }^{\prime} / \mathrm{C}_{\text {in }}{ }^{\prime}=\mathrm{C}_{\text {out }} / \mathrm{C}_{\text {in }} \times \mathrm{C}_{\text {in phenol red }} / \mathrm{C}_{\text {out phenol red }}
$$

where $\mathrm{C}_{\text {in phenol red }}$ is equal to the concentration of phenol red in the inlet sample, and $\mathrm{C}_{\text {out phenol red }}$ is equal to the concentration of phenol red in the outlet sample.
The drug absorption rate constant $\left(\mathrm{K}_{\mathrm{a}}\right)$ and the effective permeability coefficient $\left(\mathrm{P}_{\text {eff }}\right)$ were calculated using the following equations:

$$
\begin{gathered}
\mathrm{K}_{\mathrm{a}}=\left(\mathrm{C}_{\text {out }}{ }^{\prime} / \mathrm{C}_{\text {in }}{ }^{\prime}\right) \times \mathrm{Q} / \mathrm{V} \\
\mathrm{P}_{\text {eff }}=-\mathrm{Q} \times \ln \left(\mathrm{C}_{\text {out }}{ }^{\prime} / \mathrm{C}_{\text {in }}{ }^{\prime}\right) / 2 \pi \mathrm{rl}
\end{gathered}
$$

where $\mathrm{Q}$ is the perfusion solution flow rate $(0.2 \mathrm{~mL} / \mathrm{minute})$, $\mathrm{V}, \mathrm{r}$, and $\mathrm{l}$ are the volume, radius, and length of the intestine segment, respectively.

\section{Mechanisms of Pgp inhibition}

\section{Measurement of fluorescence anisotropy}

The membrane fluidity was evaluated by anisotropy measurements with the fluorescent probe DPH. ${ }^{34}$ Around $1 \mathrm{mg}$ of DPPC was dissolved in $500 \mu \mathrm{L}$ of chloroform and dried under a stream of nitrogen. After the lipids had been dried under a high vacuum for at least 2 hours, they were hydrated by adding $100 \mu \mathrm{L}$ of phosphate buffered saline of $\beta-\mathrm{CD}, \mathrm{HP}-\beta-\mathrm{CD}$ $(6.8 \mathrm{mmol} / \mathrm{L})$, or an equivalent of the inclusion complexes. Each sample was vortexed for 2 hours at $60^{\circ} \mathrm{C}$ to uniformly disperse the lipids. It was then subjected to five cycles of freeze and thaw in liquid nitrogen and a $40^{\circ} \mathrm{C}$ water bath to ensure solute equilibration between trapped and bulk solutions. The resulting liposomes $(0.15 \mathrm{mg}$ of lipids $/ \mathrm{mL})$ were incubated for $30 \mathrm{~min}$ at $37^{\circ} \mathrm{C}$ in phosphate buffered saline at a pH of 7.4 with $10 \mathrm{mM}$ DPH which was added as a 100-fold concentrated stock solution in tetrahydrofuran. The anisotropy values were determined with a Flexstation 3 microplate reader (Molecular Devices). The wavelengths of excitation and emission were 360 and $430 \mathrm{~nm}$, respectively.

\section{Determination of Pgp ATPase activity}

The ATPase activity of Pgp was determined using a luminescent ATP detection kit (Pgp-Glo Assay kit; Promega) according to the manufacturer's instructions. Briefly, $0.5 \mathrm{mg} / \mathrm{mL}$ of Pgp membranes and $5 \mathrm{mM} \mathrm{MgATP}$ were incubated in the absence or presence of $100 \mu \mathrm{M}$ sodium orthovanadate at $37^{\circ} \mathrm{C}$ for 40 minutes, and the remaining ATP was detected as a luciferase-generated luminescent signal. Basal Pgp ATPase activity was determined as the difference between ATP hydrolysis in the presence or absence of vanadate. Verapamil-stimulated Pgp ATPase activity was measured in the presence of $200 \mu \mathrm{M}$ verapamil.

\section{Statistical analysis}

Results are presented as mean \pm standard deviation. Statistical differences were calculated by one-way analysis of variance 
with Tukey's post hoc test using Origin 7.5 (OriginLab Corporation, Northampton, MA). $P<0.05$ was considered to be statistically significant.

\section{Results and discussion \\ Phase solubility studies}

The phase solubility diagrams for the icariin $/ \beta-C D$ and the icariin/HP- $\beta$-CD systems (Figure 3 ) showed drug solubility increased linearly with increasing $\beta-C D$ or $H P-\beta-C D$ concentration. The solubility increased significantly from $10.1 \times 10^{-3} \mathrm{mM}$ at $0 \mathrm{mM} \beta-\mathrm{CD}$ and HP- $\beta$-CD to $1.7 \times 10^{-2}$ $\mathrm{mM}$ and $2.2 \times 10^{-2} \mathrm{mM}$ at $18 \mathrm{mM} \beta-\mathrm{CD}$ and $\mathrm{HP}-\beta-\mathrm{CD}$. The diagrams can be classified as $\mathrm{A}_{\mathrm{L}}$ type according to the model proposed by Higuchi and Connors, ${ }^{35}$ and can be related to the formulation of inclusion complexes. The apparent 1:1 stability constant, $\mathrm{K}_{\mathrm{c}}$, was calculated from the phase solubility diagrams based on the following equation:

$$
\mathrm{K}_{\mathrm{c}}=\text { slope } / \mathrm{S}_{0}(1 \text {-slope })
$$

where slope is the value found in the linear regression and $\mathrm{S}_{0}\left(10.1 \times 10^{-3} \mathrm{mM}\right)$ is the water solubility of icariin in the absence of $\beta$-CD or HP- $\beta$-CD (intercept). This gave a $\mathrm{K}_{c}$ of $39.62 \mathrm{M}^{-1}$ and $57.73 \mathrm{M}^{-1}$ for icariin/ $\beta-\mathrm{CD}$ and icariin/ HP- $\beta$-CD systems, respectively.

\section{UV spectroscopy}

UV spectroscopy was used to further confirm the complexation of icariin with $\beta-\mathrm{CD}$ and $\mathrm{HP}-\beta-\mathrm{CD}$ in the solution. The absorption of icariin $(0.01 \mathrm{mmol} / \mathrm{L})$ at $268 \mathrm{~nm}$ gradually increased upon the addition of varying the concentration (from $0-4 \mathrm{mM}$ ) of $\beta-\mathrm{CD}$ and HP- $\beta-C D$ (Figure 4). This indicates the formation of inclu-

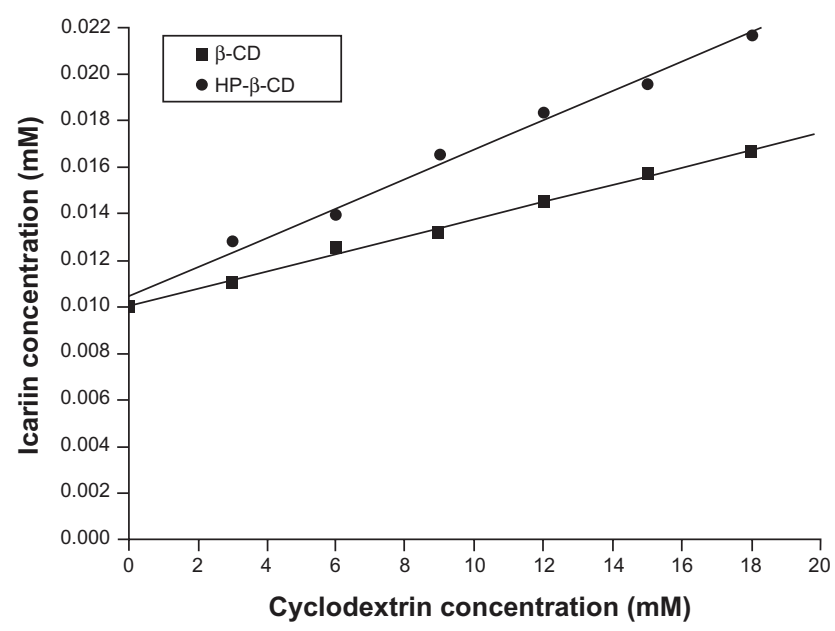

Figure 3 Phase solubility diagrams of icariin with $\beta-C D$ or HP- $\beta-C D$. Abbreviations: $\beta-C D$, beta-cyclodextrin; $H P-\beta-C D$, hydroxypropyl-beta-cyclodextrin.
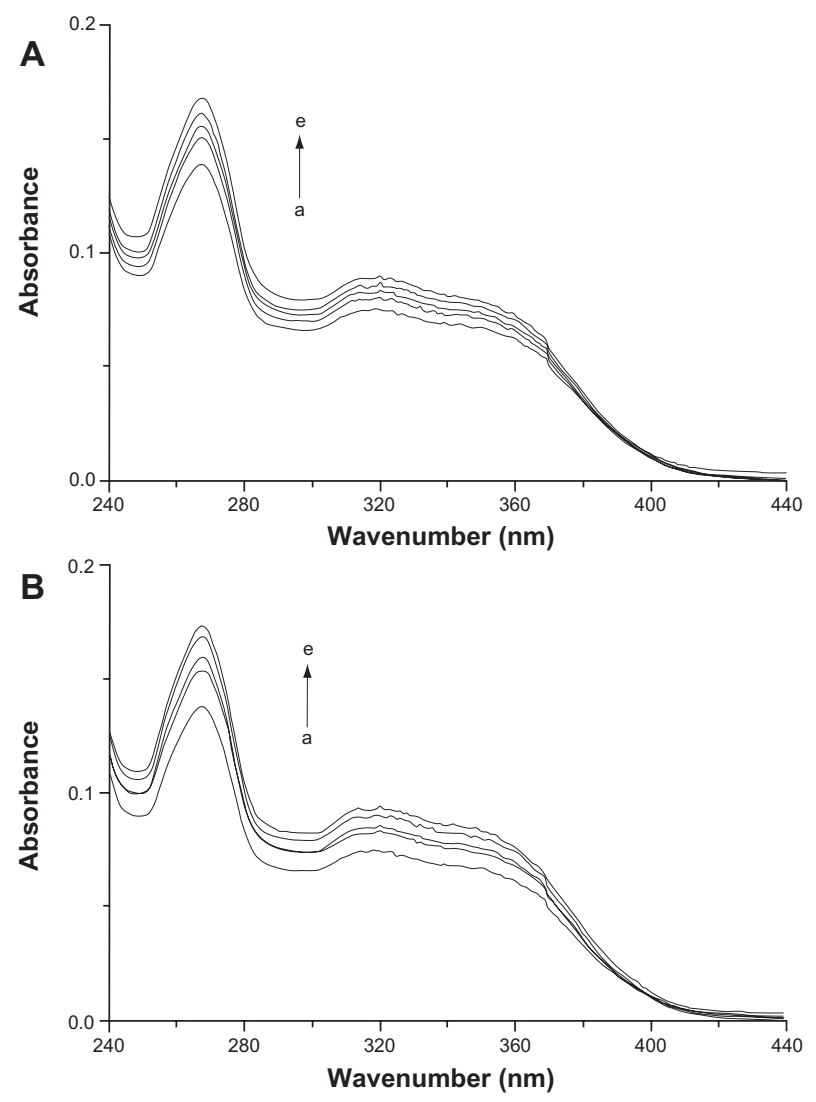

Figure 4 UV spectra of icariin in the various concentrations of $(\mathbf{A}) \beta-C D$ and $(\mathbf{B})$ HP- $\beta$-CD (from a to e): 0, 0.4, 0.8, I, $4 \mathrm{mM}$.

Abbreviations: UV, ultraviolet; $\beta-C D$, beta-cyclodextrin; HP- $\beta-C D$, hydroxypropylbeta-cyclodextrin.

sion complexes and suggests that this complexation involves the icariin chromophore entering the cyclodextrin cavity. ${ }^{36,37}$

\section{FTIR spectroscopy}

FTIR spectrograms are given in Figure 5. The free icariin had intense absorptions peaks at $1598 \mathrm{~cm}^{-1}, 1509 \mathrm{~cm}^{-1}$, $1073 \mathrm{~cm}^{-1}, 1259 \mathrm{~cm}^{-1}$, and $1652 \mathrm{~cm}^{-1}$, which were the characteristic peaks for identification. The spectrums of $\beta-C D$ and HP- $\beta-C D$ presented characteristic peaks at $3359 \mathrm{~cm}^{-1}$ and $3364 \mathrm{~cm}^{-1}$, respectively. The absorption peaks of icariin appeared unchanged in the physical mixtures. This indicated that no interaction occurred during simply physical mixing of the free drug and $\beta-C D$ or HP- $\beta-C D$. The spectrums of the icariin/ $\beta-\mathrm{CD}$ and icariin/HP- $\beta-\mathrm{CD}$ inclusion complexes showed the broad peak at around $3380 \mathrm{~cm}^{-1}$ and $3371 \mathrm{~cm}^{-1}$, and less-intense absorptions at around $1598 \mathrm{~cm}^{-1}, 1509 \mathrm{~cm}^{-1}$, $1073 \mathrm{~cm}^{-1}, 1259 \mathrm{~cm}^{-1}$, and $1652 \mathrm{~cm}^{-1}$. These results indicated that some functional groups of icariin might be included in the cavity of $\beta-C D$ or HP- $\beta-C D$ molecules to form the inclusion complexes. No new peaks were observed in the FTIR spectra of the icariin/ $\beta-C D$ inclusion complex or the icariin/ 


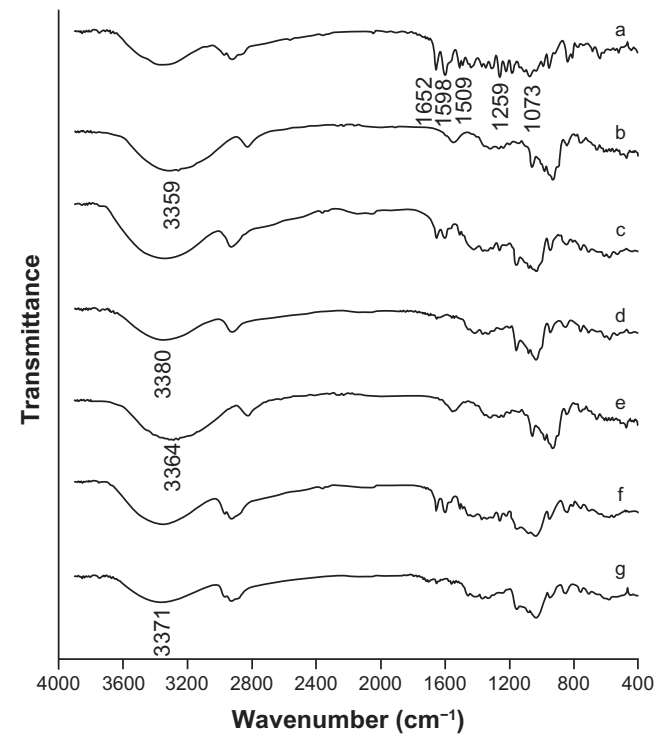

Figure 5 FTIR spectrograms of the inclusion complexes. (a) icariin, (b) $\beta-C D$, (c) the icariin/ $\beta-C D$ physical mixture, (d) the icariin $/ \beta-C D$ inclusion complex. (e) HP- $\beta-C D$, (f) the icariin/HP- $\beta-C D$ physical mixture, and (g) the icariin/HP- $\beta-C D$ inclusion complex.

Abbreviations: FTIR, Fourier transform infrared; $\beta-C D$, beta-cyclodextrin; HP- $\beta-C D$, hydroxypropyl-beta-cyclodextrin.

HP- $\beta$-CD inclusion complex, indicating that no chemical bonds were created in the formation of this complex.

\section{Differential scanning calorimetry}

DSC spectrograms are given in Figure 6. The thermogram of icariin was typical of that of a highly crystalline

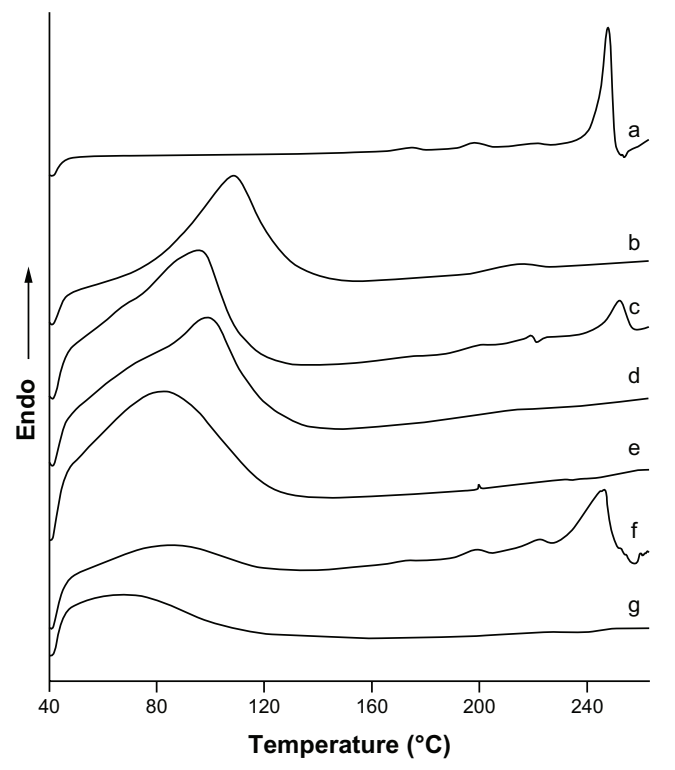

Figure 6 DSC thermograms for the inclusion complexes. (a) icariin, (b) $\beta-C D$, (c) the icariin $/ \beta-C D$ physical mixture, (d) the icariin/ $\beta-C D$ inclusion complex. (e) HP- $\beta-C D$, (f) the icariin/HP- $\beta-C D$ physical mixture, and (g) the icariin/HP- $\beta-C D$ inclusion complex.

Abbreviations: DSC, differential scanning calorimetry; $\beta-C D$, beta-cyclodextrin; HP- $\beta-C D$, hydroxypropyl-beta-cyclodextrin. compound, showing a fusion endothermic peak at $247.57^{\circ} \mathrm{C}$ $(\Delta \mathrm{H}=103.25 \mathrm{~J} / \mathrm{g})$. The thermograms of $\beta-\mathrm{CD}$ and $\mathrm{HP}-\beta-\mathrm{CD}$ exhibited a very broad endothermic peak between $40^{\circ} \mathrm{C}$ and $140^{\circ} \mathrm{C}$ because of the loss of water molecules from the cyclodextrin cavity. In the thermal curve of the physical mixtures, the fusion endothermic peak of icariin was much lower than that of the crystalline substance and shifted to a lower temperature as a consequence of the interaction between icariin and $\beta-C D$ or HP- $\beta-C D$. However, this interaction could be induced by the thermal energy supplied to the sample in the DSC scan. ${ }^{38}$ In contrast, there were no sharp peaks attributable to the crystalline form of icariin in the inclusion complexes, indicating that icariin was no longer present as a crystalline form, but was converted into an amorphous state.

\section{Powder X-ray diffractometry}

XRD was another valid strategy used to confirm the cyclodextrin complexation in powder or microcrystalline states. The diffraction pattern of the drug/CD complex should be clearly distinct from that containing the individual components of the inclusion complex. As shown in Figure 7, XRD patterns clearly confirmed the crystalline nature of both icariin and $\beta-C D$, as well as the amorphous state of HP- $\beta-C D$. The XRD patterns of the physical mixture confirmed the presence of both compounds as isolated solids, because the diffractograms were simply the superposition of each component. The peaks in the diffractogram of the icariin/ $/$-CD inclusion complex reduced in number and intensity when

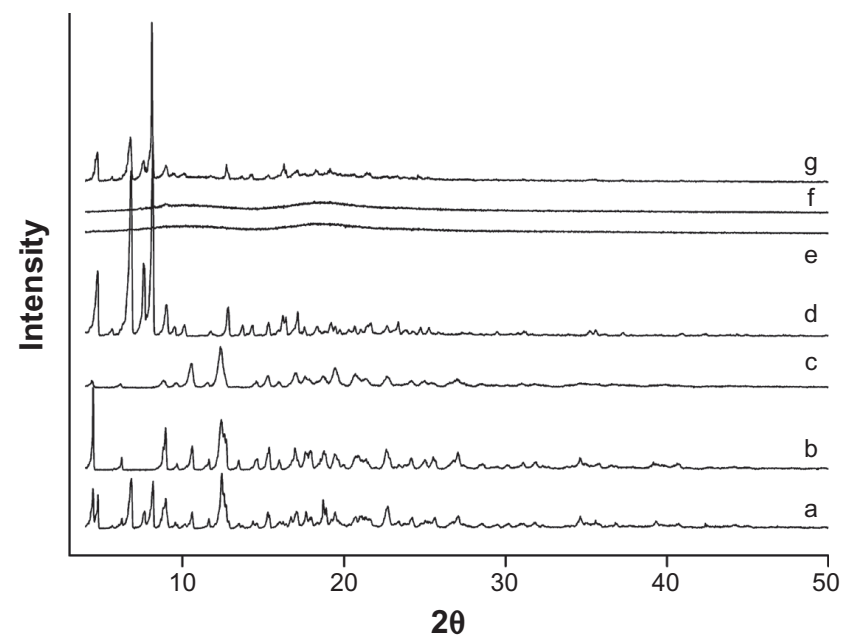

Figure $7 \times$-ray diffractograms for the inclusion complexes. (a) icariin, (b) $\beta-C D$, (c) the icariin $/ \beta-C D$ inclusion complex, (d) the icariin $/ \beta-C D$ physical mixture, (e) HP- $\beta-C D$, (f) the icariin/HP- $\beta-C D$ inclusion complex, and (g) the icariin/ HP- $\beta-C D$ physical mixture.

Abbreviations: $\beta-C D$, beta-cyclodextrin; $H P-\beta-C D$, hydroxypropyl-beta-cyclodextrin. 
compared to icariin and $\beta-\mathrm{CD}$. The diffractograms of the icariin/HP- $\beta$-CD inclusion complex showed a typical diffuse pattern, indicating a loss of crystallinity of icariin. Moreover, the intensity differences observed on the diffractograms of HP- $\beta-C D$ and the inclusion complexes in the $3-50^{\circ}(2 \theta)$ range, strengthen the theory that the inclusion complexes had been formed given that an approximately 1.5 -fold intensity decrease was observed after complexation. After taking into account the results of the DSC and FTIR spectroscopy, we can assume that the formation of new solid phases might be due to the formation of the icariin/ $\beta$-CD inclusion complex and the icariin/HP- $\beta-C D$ inclusion complex.

\section{Two-dimensional 'H NMR spectroscopy}

The $2 \mathrm{D}{ }^{1} \mathrm{H}$ NMR is a powerful tool used for investigating inter- and intramolecular interactions, because the presence of nuclear Overhauser effect cross-peaks between the protons from two different species indicate spatial contact within $0.4 \mathrm{~nm} .{ }^{39}$ Furthermore, it is an effective method to study spatial conformations of CD inclusion complexes. ${ }^{40,41}$ To gain more confirmatory information, we obtained 2D ROESY of the icariin inclusion complex with $\beta-\mathrm{CD}$ or HP- $\beta-\mathrm{CD}$. These studies were conducted in $\mathrm{D}_{2} \mathrm{O}$ and DMSO- $\mathrm{d}_{6}(50: 50, \mathrm{v} / \mathrm{v})$ due to solubility constraints. The essential feature of the interaction of icariin with CD in DMSO should be similar to that in water due to the similar relative magnitude of the dielectric constants of DMSO and $\mathrm{H}_{2} \mathrm{O}(\varepsilon=46.8$ and 80, respectively). ${ }^{36}$ The ${ }^{1} \mathrm{H}$ resonance of icariin was assigned as follows (Figure 8): ${ }^{1} \mathrm{H}-\mathrm{NMR}\left(500 \mathrm{MHz}, \mathrm{D}_{2} \mathrm{O}: \mathrm{DMSO}_{6} \mathrm{~d}_{6}\right.$ [50:50, v/v]) $\delta: 7.87\left(2 \mathrm{H}, \mathrm{d}, \mathrm{J}=8.5 \mathrm{~Hz}, \mathrm{H}-2^{\prime}, 6^{\prime}\right), 7.20(2 \mathrm{H}$, d, J = 8.5 Hz, H-3', 5'), 6.73 (1H, s, H-6), 5.29 (1H, brs, rha$\mathrm{H}-1), 5.19\left(1 \mathrm{H}, \mathrm{m}, \mathrm{H}-2^{\prime \prime}\right), 3.94\left(3 \mathrm{H}, \mathrm{s}, \mathrm{OCH}_{3}\right), 1.73(1 \mathrm{H}, \mathrm{s}$, H-5"), 1.66 (1H, s, H-4"), 0.86 (3H, d, J = 6.0 Hz, rha-H-6). The 2D ROESY spectrums of the inclusion complexes are shown in Figure 9. Cross-peaks were observed between the
H- $2^{\prime}$ and $\mathrm{H}-\mathrm{6}^{\prime}$ protons of icariin and the $\mathrm{H}-3$ and $\mathrm{H}-5$ protons of $\beta$-CD or HP- $\beta$-CD. The cross-peaks between 7-glucosyl group and 3-rhamnose group protons of icariin and $\beta-C D$ or HP- $\beta-C D$ were not definite due to problems associated with overlap of the cross-peaks. Regarding the solubility of the 7-glucosyl group and the 3-rhamnose group of icariin, we propose that it is the aromatic ring of icariin, not the 7-glucosyl group or the 3-rhamnose group of icariin, that are included in the $\beta-C D$ or HP- $\beta-C D$ nanocavity.

Some insights into the inclusion mode were gained by molecular dynamics simulations using the Amber force field and the semiempirical method Parameterized Model 3. The optimized structure of the icariin/ $\beta$-CD inclusion complex and the icariin/HP- $\beta-C D$ inclusion complex are shown in Figure 10. The icariin/HP- $\beta-\mathrm{CD}$ inclusion complex and the icariin/ $\beta-C D$ inclusion complex have a similar inclusion structure (ie, the phenoxymethyl fragment of icariin is included in both the $\beta-\mathrm{CD}$ and HP- $\beta-\mathrm{CD}$ cavity). However, the phenoxymethyl fragment of icariin penetrates deeper into the cavity of HP- $\beta-\mathrm{CD}$ than $\beta-\mathrm{CD}$. The energy of the icariin/HP- $\beta-C D$ inclusion complex $(-30180 \mathrm{kcal} / \mathrm{mol})$ is smaller than that of the icariin/ $\beta$-CD inclusion complex $(-23681 \mathrm{kcal} / \mathrm{mol})$, suggesting that the icariin/HP- $\beta-\mathrm{CD}$ inclusion complex is more stable than icariin/ $\beta-C D$ inclusion complex. This result is consistent with the results of phase solubility studies.

\section{In situ absorption studies}

In situ perfusion technique was performed to evaluate the effect of the inclusion complexes on the absorption of icariin as it provides a greater correlation with intestinal absorption in humans than Caco-2 and MDCK cell lines. ${ }^{42}$ During the perfusion experiment, icariin was stable in the perfusion solution at $37^{\circ} \mathrm{C}$ and no absorption was observed either to the inlet and outlet tubes, or to the plastic vials. As shown

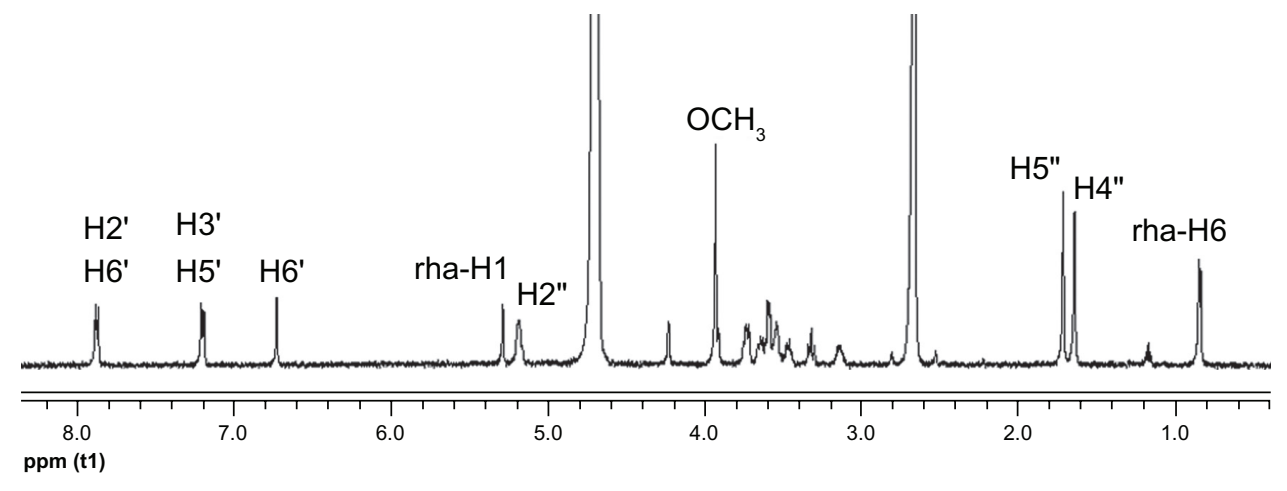

Figure 8 ' $\mathrm{H}$ NMR spectra of icariin in $\mathrm{D}_{2} \mathrm{O}$ and DMSO-d $\mathrm{d}_{6}(50: 50, \mathrm{v} / \mathrm{v})$ at $25^{\circ} \mathrm{C}$.

Abbreviations: 'H NMR, proton nuclear magnetic resonance; DMSO- $\mathrm{d}_{6}$, deuterated dimethyl sulfoxide; v/v, volume-to-volume; $\mathrm{H}$, hydrogen. 

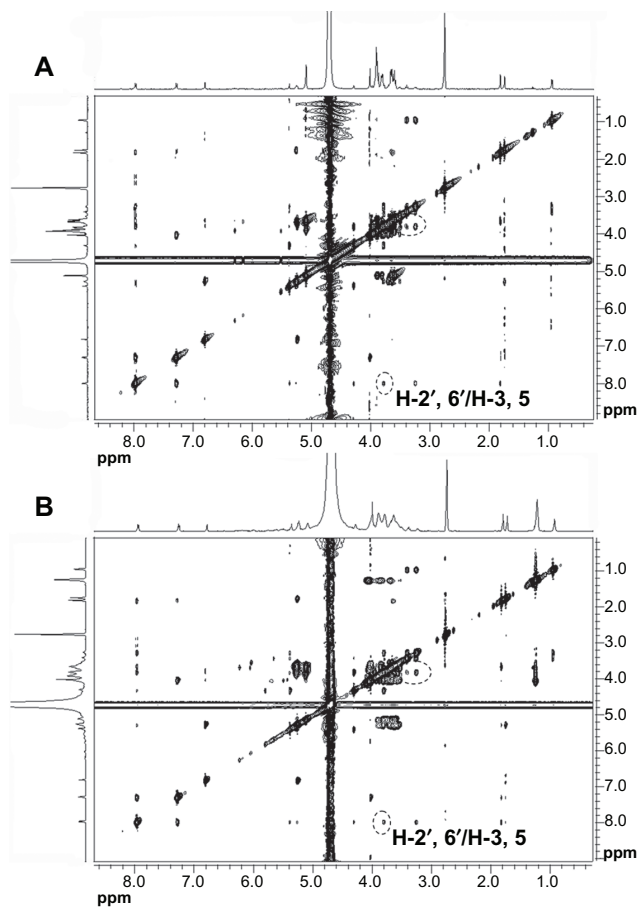

Figure 9 ROESY spectrums of $(\mathbf{A})$ the icariin/ $\beta-C D$ inclusion complex and (B) the icariin/HP- $\beta-C D$ inclusion complex.

Abbreviations: ROESY, rotating-frame Overhauser effect spectroscopy; $\beta-C D$, beta-cyclodextrin; HP- $\beta-C D$, hydroxypropyl-beta-cyclodextrin.
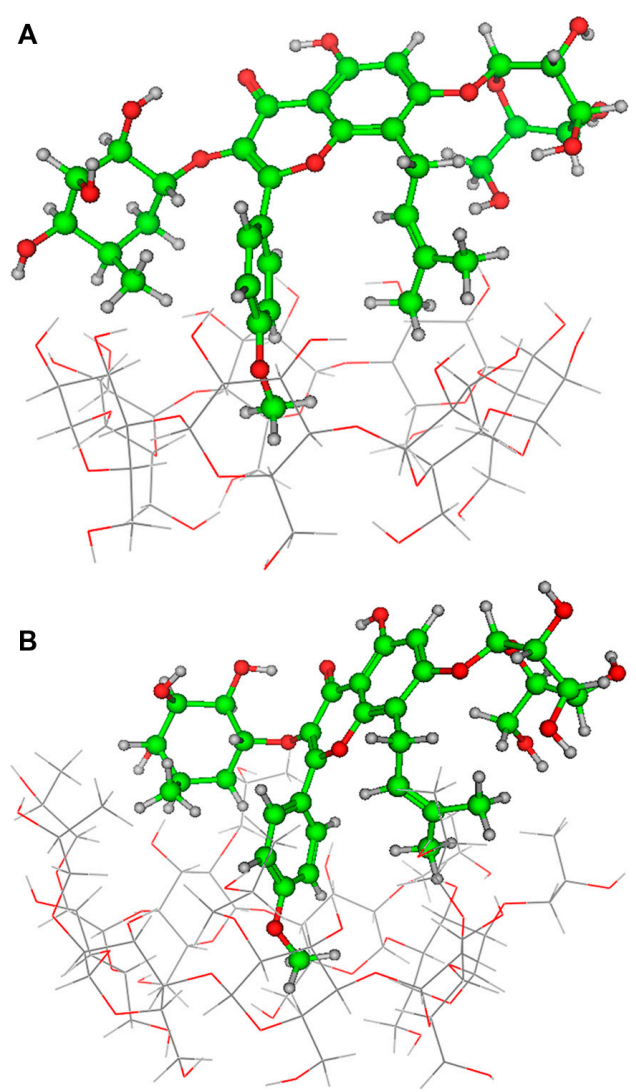

Figure 10 Optimized inclusion structures of $(\mathbf{A})$ the icariin/ $\beta-C D$ inclusion complex and (B) the icariin/HP- $\beta-C D$ inclusion complex.

Abbreviations: $\beta-C D$, beta-cyclodextrin; $H P-\beta-C D$, hydroxypropyl-beta-cyclodextrin. in Figure 11, the presence of verapamil significantly increased the absorption rate and the permeability of icariin $\left(\mathrm{K}_{\mathrm{a}}=7.92 \times 10^{-3} \mathrm{~min}^{-1}, \mathrm{P}_{\text {eff }}=3.01 \times 10^{-3} \mathrm{~cm} / \mathrm{min}\right)$. This improvement indicated that intestinal Pgp was involved in icariin intestinal absorption. When compared to icariin alone, the icariin/ $\beta-C D$ inclusion complex gave a 1.49 - and $1.55-$ fold absorption rate and permeability rate, respectively. For the icariin/HP- $\beta$-CD inclusion complex, the absorption rate was further improved and was 2.32 -fold higher than icariin alone. Similarly, the permeability rate showed a 3.46 -fold increase when compared to icariin alone. A more substantial increase in intestinal absorption was seen with the icariin/ HP- $\beta$-CD inclusion complex. This enhancement may be attributed to both the solubility enhancement and/or the Pgp inhibitory effect of both $\beta-\mathrm{CD}$ and HP- $\beta-\mathrm{CD}$.

\section{Mechanisms of Pgp inhibition}

The mechanisms by which $\beta-C D$ and HP- $\beta$-CD inhibit Pgp activity may be different from that of other Pgp inhibitors,

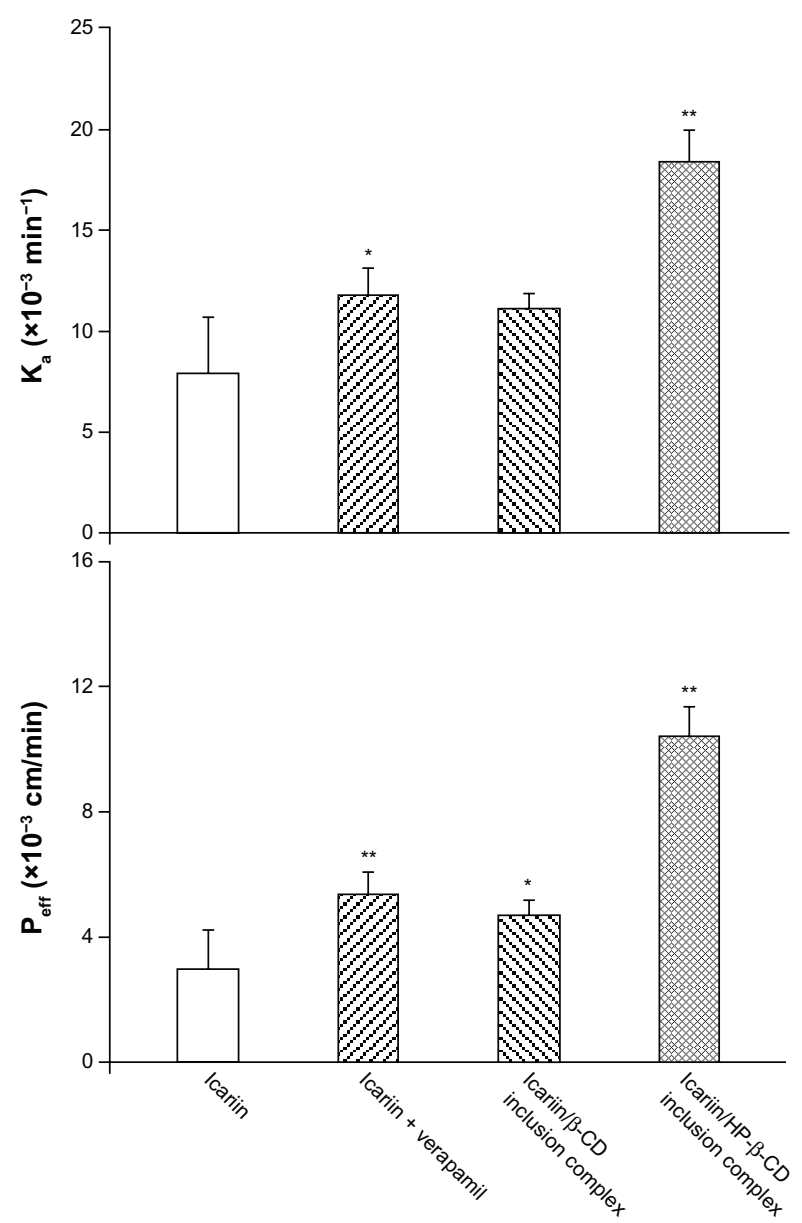

Figure I I Absorption rate $(\mathbf{A})$ and permeability $(\mathbf{B})$ of the inclusion complexes. Note: $* P<0.05$, $* * P<0.01$, significantly different from icariin alone.

Abbreviations: $\beta-C D$, beta-cyclodextrin; $H P-\beta-C D$, hydroxypropyl-beta-cyclodextrin. 
such as cyclosporine A, quinidine, and verapamil. ${ }^{43}$ Pgp recognizes many compounds as substrates, and tends to have a high affinity with hydrophobic and positively charged compounds at a certain physiological $\mathrm{pH} .{ }^{44} \beta-\mathrm{CD}$ and $\mathrm{HP}-\beta-\mathrm{CD}$ do not appear to be substrates of Pgp because they are both hydrophilic and are electrically neutral cyclic oligosaccharides with a relatively high molecular weight. ${ }^{45}$ Furthermore, $\beta-C D$ and HP- $\beta-C D$ should not compete with Pgp substrates because of their lack of cell permeability. ${ }^{27}$ Thus, $\beta-C D$ and HP- $\beta-C D$ must have an alternative inhibitory effect on Pgp activity that differs from the other Pgp inhibitors described above.

To mimic the interactions between $\beta-C D$ or HP- $\beta-C D$ and the cell membrane, a DPPC bilayer membrane was formed, and fluorescence polarization measurements were used to detect any change in the dynamic properties of DPPC induced by $\beta-\mathrm{CD}$ or HP- $\beta-\mathrm{CD} .{ }^{46}$ High anisotropy values indicate high membrane rigidity and low bilayer fluidity. As shown in Figure 12A, $\beta$-CD and HP- $\beta$-CD did not change the membrane fluidity when compared to the DPPC bilayer.
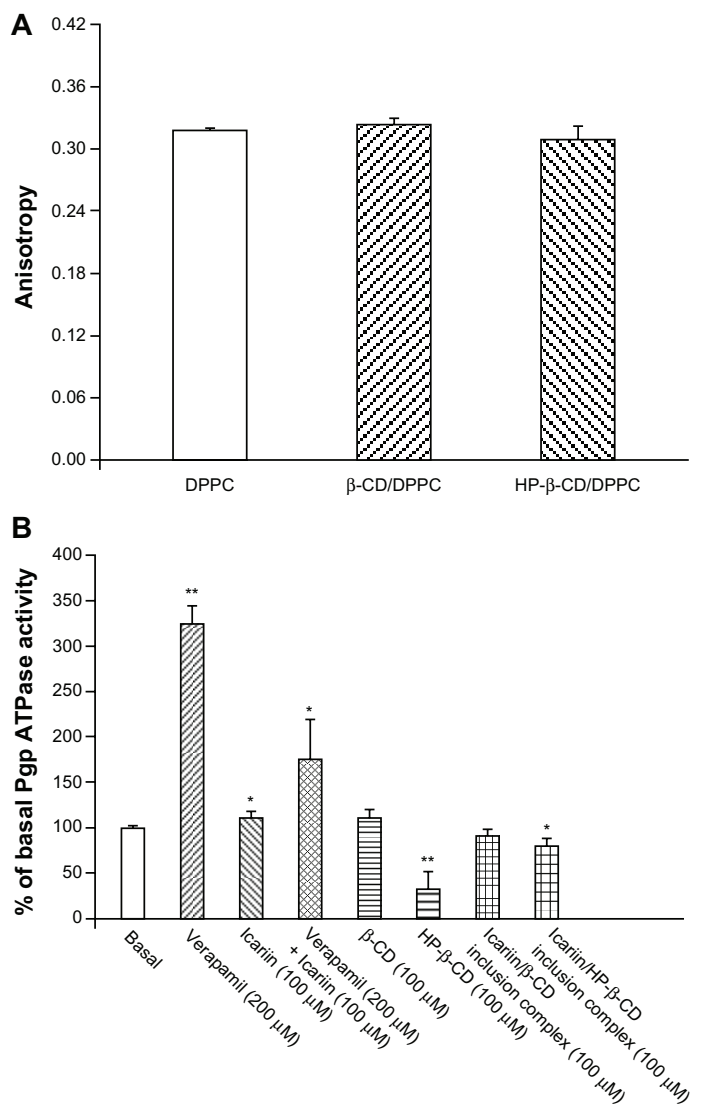

Figure 12 (A) DPH anisotropy values of the DPPC bilayer membrane, containing either $\beta-C D$ or HP- $\beta-C D$. (B) Effects of $\beta-C D$ and HP- $\beta-C D$ on PgP ATPase activity.

Notes: $* P<0.05,{ }^{*} * P<0.001$, significantly different from the basal Pgp ATPase activity. Abbreviations: DPH, 6-diphenyl-1,3,5-hexatriene; DPPC, I,2-dipalmitoyl-snglycero-3-phosphocholine; Pgp ATPase, P-glycoprotein adenosine triphosphatase; $\beta-C D$, beta-cyclodextrin; HP- $\beta-C D$, hydroxypropyl-beta-cyclodextrin.
Pgp is an ATP-dependent efflux pump; therefore, Pgp ATPase activity plays an important role in the mechanisms of Pgp inhibition. ${ }^{47}$ The influences of $\beta-C D$ and HP- $\beta-C D$ on the ATPase activity of Pgp were measured using recombinant human Pgp membranes (Figure 12B). Verapamil, a known substrate of Pgp, stimulated Pgp ATPase activity. Icariin alone stimulated the basal Pgp ATPase activity and inhibited the verapamil-stimulated Pgp ATPase activity. These results suggest that icariin is a substrate of Pgp, and competitively interacts at the drug-binding site of Pgp. $\beta-C D$ and the icariin/ $\beta-C D$ inclusion complex did not alter the Pgp ATPase activity, while HP- $\beta-\mathrm{CD}$ and the icariin/HP- $\beta-\mathrm{CD}$ inclusion complex significantly inhibited the Pgp ATPase activity. HP- $\beta$-CD might reduce the use of ATP by Van der Waals forces or hydrophobic interactions between HP- $\beta$-CD chains and the ATP binding site, or through steric perturbation, which blocks an allosteric site relevant for Pgp activity.

\section{Conclusion}

The molecular association of icariin with $\beta-C D$ and HP- $\beta-C D$ was determined. The phase-solubility profile indicated that the icariin/HP- $\beta$-CD inclusion complex showed the highest solubility, followed by the icariin/ $\beta-\mathrm{CD}$ inclusion complex, and then icariin alone. The ${ }^{1} \mathrm{H}$ NMR spectroscopy and molecular modeling studies revealed that the phenoxymethyl fragment of icariin was held within the lipophilic nanocavity of $\beta-C D$ or HP- $\beta-C D$. Results obtained by DSC, XRD, and SEM supported the complex formation in solid phase. The intestinal transport of icariin was Pgp-dependent. The icariin/ $\beta-C D$ inclusion complex improved the intestinal absorption of icariin by enhancing solubility, while the icariin/HP- $\beta-C D$ inclusion complex both enhanced solubility and inhibited the Pgp efflux pump. Unlike other Pgp inhibitors, the icariin/HP- $\beta$-CD inclusion complex does not alter membrane fluidity; rather, its inhibitory action is due to its effect on Pgp ATPase activity.

\section{Acknowledgments}

This work was financed by the National Natural Science Foundation of China (No 30570495 and 81173469), and by the Program for New Century Excellent Talents in University (No NCET-09-0899). We thank the Institute of Materia Medica, the Chinese Academy of Medical Sciences, and the Peking Union Medical College for performing the 2D ROESY NMR spectroscopies.

\section{Disclosure}

The authors report no conflicts of interest in this work. 


\section{References}

1. Frew SE, Sammut SM, Shore AF, et al. Chinese health biotech and the billion-patient market. Nature Biotechnol. 2008;26(1):37-53.

2. Zhang G, Qin L, Shi Y. Epimedium-derived phytoestrogen flavonoids exert beneficial effect on preventing bone loss in late postmenopausal women: a 24-month randomized, double-blind and placebo-controlled trial. J Bone Miner Res. 2007;22(7):1072-1079.

3. Makarova MN, Pozharitskaya ON, Shikov AN, Tesakova SV, Makarov VG, Tikhonov VP. Effect of lipid-based suspension of Epimedium koreanum Nakai extract on sexual behavior in rats. J Ethnopharmacol. 2007;114(3):412-416.

4. Meng FH, LiYB, Xiong ZL, Jiang ZM, Li FM. Osteoblastic proliferative activity of Epimedium brevicornum Maxim. Phytomedicine. 2005; 12(3):189-193.

5. Pan Y, Zhang WY, Xia X, Kong LD. Effects of icariin on hypothalamicpituitary-adrenal axis action and cytokine levels in stressed SpragueDawley rats. Biol Pharm Bull. 2006;29(12):2399-2403.

6. Pan Y, Kong L, Xia X, Zhang W, Xia Z, Jiang F. Antidepressant-like effect of icariin and its possible mechanism in mice. Pharmacol Biochem Behav. 2005;82(4):686-694.

7. Huang X, Zhu D, Lou Y. A novel anticancer agent, icaritin, induced cell growth inhibition, G1 arrest and mitochondrial transmembrane potential drop in human prostate carcinoma PC-3 cells. Eur J Pharmacol. 2007;564(1-3):26-36.

8. Mo SF, Zhou F, Lv YZ, Hu QH, Zhang DM, Kong LD. Hypouricemic action of selected flavonoids in mice: structure-activity relationships. Biol Pharm Bull. 2007;30(8):1551-1556.

9. Li F, Gong QH, Wu Q, Lu YF, Shi JS. Icariin isolated from Epimedium brevicornum Maxim attenuates learning and memory deficits induced by d-galactose in rats. Pharmacol Biochem Behav. 2010;96(3): 301-305.

10. Xin ZC, Kim EK, Lin CS, et al. Effects of icariin on cGMP-specific PDE5 and cAMP-specific PDE4 activities. Asian J Androl. 2003; 5(1):15-18.

11. Zhang YP, Xu W, Li N, et al. LC-MS-MS method for simultaneous determination of icariin and its active metabolite icariside II in human plasma. Chromatographia. 2008;68(3-4):245-250.

12. Xu W, Zhang Y, Yang M, et al. LC-MS/MS method for the simultaneous determination of icariin and its major metabolites in rat plasma. J Pharm Biomed Anal. 2007;45(4):667-672.

13. Cheng S, Qiu F, Wang S, He J. HPLC analysis and pharmacokinetics of icariin in rats. $J$ Sep Sci. 2007;30(9):1307-1312.

14. Chao J, Wang $\mathrm{H}$, Zhao $\mathrm{W}$, Zhang $\mathrm{M}$, Zhang L. Investigation of the inclusion behavior of chlorogenic acid with hydroxypropyl- $\beta$ cyclodextrin. Int J Biol Macromol. 2012;50(1):277-282.

15. Loftsson T, Hreinsdottir D, Masson M. Evaluation of cyclodextrin solubilization of drugs. Int J Pharm. 2005;302(1-2):18-28

16. Rajewski RA, Stella VJ. Pharmaceutical applications of cyclodextrins. 2. In vivo drug delivery. J Pharm Sci. 1996;85(11):1142-1169.

17. Li J, Xiao H, Li J, Zhong Y. Drug carrier systems based on watersoluble cationic beta-cyclodextrin polymers. Int J Pharm. 2004;278(2): 329-342.

18. Liu J, Qiu L, Gao J, Jin Y. Preparation, characterization and in vivo evaluation of formulation of baicalein with hydroxypropyl-betacyclodextrin. Int J Pharm. 2006;312(1-2):137-143.

19. Kano K, Kitagishi H, Tanaka S. Characterization of an inclusion complex of 5,10,15,20-tetrakis(4-sulfonatophenyl)-porphinato iron and an $\mathrm{O}$-methylated $\beta$-cyclodextrin dimer having a pyridine linker and its related complexes in aqueous solution. J Incl Phenom Macrocycl Chem. 2006;56(1-2):69-74.

20. Gould S, Scott RC. 2-Hydroxypropyl-beta-cyclodextrin (HP-beta-CD): a toxicology review. Food Chem Toxicol. 2005; 43(10): 1451-1459.

21. Castronuovo G, Niccoli M. Thermodynamics of inclusion complexes of natural and modified cyclodextrins with propranolol in aqueous solution at 298 K. Bioorg Med Chem. 2006;14(11):3883-3887.
22. Challa R, Ahuja A, Ali J, Khar RK. Cyclodextrins in drug delivery: an updated review. AAPS Pharm Sci Tech. 2005;6(2):E329-E357.

23. Brewster ME, Loftsson T. The use of chemically modified cyclodextrins in the development of formulations for chemical delivery systems. Pharmazie. 2002;57(2):94-101.

24. Davis ME, Brewster ME. Cyclodextrin-based pharmaceutics: past, present and future. Nat Rev Drug Discov. 2004;3(12):1023-1035.

25. Duchene D, Wouessidjewe D, Ponchel G. Cyclodextrins and carrier systems. J Control Release. 1999;62(1-2):263-268.

26. Irie T, Uekama K. Pharmaceutical applications of cyclodextrins. III. Toxicological issues and safety evaluation. J Pharm Sci. 1997;86(2): 147-162.

27. Arima H, Yunomae K, Hirayama F, Uekama K. Contribution of P-glycoprotein to the enhancing effects of dimethyl-beta-cyclodextrin on oral bioavailability of tacrolimus. J Pharmacol Exp Ther. 2001;297(2):547-555.

28. Meyer dos Santos S, Weber CC, Franke C, Muller WE, Eckert GP. Cholesterol: Coupling between membrane microenvironment and ABC transporter activity. Biochem Biophys Res Commun. 2007;354(1): 216-221.

29. Fenyvesi F, Fenyvesi E, Szente L, et al. P-glycoprotein inhibition by membrane cholesterol modulation. Eur J Pharm Sci. 2008;34(4-5): 236-242.

30. Cai C, Zhu H, Chen J. Overexpression of caveolin-1 increases plasma membrane fluidity and reduces P-glycoprotein function in Hs578T/ Dox. Biochem Biophys Res Commun. 2004;320(3):868-874.

31. Calabro ML, Tommasini S, Donato P, et al. The rutin/beta-cyclodextrin interactions in fully aqueous solution: spectroscopic studies and biological assays. J Pharm Biomed Anal. 2005;36(5):1019-1027.

32. Kunes M, Svoboda Z, Kvetina J, Herout V, Herink J, Bajgar J. Intestinal single-pass in situ perfusion technique in rat: the influence of L-carnitine on absorption of 7-methoxytacrine. Biomed Pap Med Fac Univ Palacky, Olomouc Czech Repub. 2005;149(2):433-435.

33. Nornoo AO, Zheng H, Lopes LB, Johnson-Restrepo B, Kannan K, Reed R. Oral microemulsions of paclitaxel: in situ and pharmacokinetic studies. Eur J Pharm Biopharm. 2009;71(2):310-317.

34. Belli S, Elsener PM, Wunderli-Allenspach H, Kramer SD. Cholesterol-mediated activation of P-glycoprotein: distinct effects on basal and drug-induced ATPase activities. J Pharm Sci. 2009;98(5): 1905-1918.

35. Higuchi T, Connors K. Phase solubility techniques. Advances in Analytical Chemistry and Instrumentation. 1965;7:117-212.

36. Yang H, Parniak MA, Isaacs CE, Hillier SL, Rohan LC. Characterization of cyclodextrin inclusion complexes of the anti-HIV non-nucleoside reverse transcriptase inhibitor UC781. AAPS J. 2008;10(4): 606-613.

37. Badr-Eldin SM, Elkheshen SA, Ghorab MM. Inclusion complexes of tadalafil with natural and chemically modified beta-cyclodextrins. I: preparation and in-vitro evaluation. Eur J Pharm Biopharm. 2008; 70(3):819-827.

38. Cappello B, Di Maio C, Iervolino M, Miro A. Improvement of solubility and stability of valsartan by hydroxypropyl-beta-cyclodextrin. $J$ Incl Phenom Macrocycl Chem. 2006;54(3-4):289-294.

39. Schneider HJ, Hacket F, Rudiger V, Ikeda H. NMR studies of cyclodextrins and cyclodextrin complexes. Chem Rev. 1998;98(5):1755-1786.

40. de Araujo MV, Vieira EK, Silva Lazaro G, et al. Sulfadiazine/ hydroxypropyl-beta-cyclodextrin host-guest system: Characterization, phase-solubility and molecular modeling. Bioorg Med Chem. 2008;16(10):5788-5794.

41. Jullian C, Orosteguis T, Perez-Cruz F, Sanchez P, Mendizabal F, Olea-Azar C. Complexation of morin with three kinds of cyclodextrin. A thermodynamic and reactivity study. Spectrochim Acta A Mol Biomol Spectrosc. 2008;71(1):269-275.

42. Salphati L, Childers K, Pan L, Tsutsui K, Takahashi L. Evaluation of a single-pass intestinal-perfusion method in rat for the prediction of absorption in man. J Pharm Pharmacol. 2001;53(7):1007-1013. 
43. Eckford PD, Sharom FJ. ABC efflux pump-based resistance to chemotherapy drugs. Chem Rev. 2009;109(7):2989-3011.

44. Zhou S, Lim LY, Chowbay B. Herbal modulation of P-glycoprotein. Drug Metab Rev. 2004;36(1):57-104.

45. Teodori E, Dei S, Scapecchi S, Gualtieri F. The medicinal chemistry of multidrug resistance (MDR) reversing drugs. Farmaco. 2002;57(5): $385-415$.
46. Dai F, Liu W. Enhanced gene transfection and serum stability of polyplexes by PDMAEMA-polysulfobetaine diblock copolymers. Biomaterials. 2011;32(2):628-638.

47. Collnot EM, Baldes C, Wempe MF, et al. Mechanism of inhibition of P-glycoprotein mediated efflux by vitamin E TPGS: influence on ATPase activity and membrane fluidity. Mol Pharm. 2007;4(3): 465-474.
International Journal of Nanomedicine

\section{Publish your work in this journal}

The International Journal of Nanomedicine is an international, peerreviewed journal focusing on the application of nanotechnology in diagnostics, therapeutics, and drug delivery systems throughout the biomedical field. This journal is indexed on PubMed Central, MedLine, CAS, SciSearch ${ }^{\circledR}$, Current Contents ${ }^{\circledR} /$ Clinical Medicine,

\section{Dovepress}

Journal Citation Reports/Science Edition, EMBase, Scopus and the Elsevier Bibliographic databases. The manuscript management system is completely online and includes a very quick and fair peer-review system, which is all easy to use. Visit http://www.dovepress.com/ testimonials.php to read real quotes from published authors.

\footnotetext{
Submit your manuscript here: http://www.dovepress.com/international-journal-of-nanomedicine-journal
} 